Liliam Pereira de Lima'

Julio da Motta Singer"

Paulo Hilário do Nascimento

Saldiva"II

\section{Spatial analysis of urban violence based on emergency room data}

\author{
Análise espacial da violência urbana \\ baseada em dados de pronto-socorro
}

\begin{abstract}
OBJECTIVE: To estimate the spatial intensity of urban violence events using wavelet-based methods and emergency room data.

METHODS: Information on victims attended at the emergency room of a public hospital in the city of São Paulo, Southeastern Brazil, from January 1, 2002 to January 11, 2003 were obtained from hospital records. The spatial distribution of 3,540 events was recorded and a uniform random procedure was used to allocate records with incomplete addresses. Point processes and wavelet analysis technique were used to estimate the spatial intensity, defined as the expected number of events by unit area.
\end{abstract}

RESULTS: Of all georeferenced points, 59\% were accidents and 40\% were assaults. There is a non-homogeneous spatial distribution of the events with high concentration in two districts and three large avenues in the southern area of the city of São Paulo.

CONCLUSIONS: Hospital records combined with methodological tools to estimate intensity of events are useful to study urban violence. The wavelet analysis is useful in the computation of the expected number of events and their respective confidence bands for any sub-region and, consequently, in the specification of risk estimates that could be used in decision-making processes for public policies.

DESCRIPTORS: Violence. Urban Zones. Medical Records. Geographic Information Systems. Statistical Methods and Procedures. Intensity of point processes.
Logx Assessoria Financeira e Estatística. São Paulo, SP, Brasil

" Instituto de Matemática e Estatística. Universidade de São Paulo (USP). São Paulo, SP, Brasil

III Faculdade de Medicina. USP. São Paulo, SP, Brasil

Correspondence:

Liliam Pereira de Lima

R. Carlos Weber, 457

05303-000 São Paulo, SP, Brasil

E-mail: Iplima@terra.com.br 


\section{RESUMO}

OBJETIVO: Estimar a intensidade espacial de eventos violentos utilizando metodologia estatística baseada em ondaletas (wavelets) e em dados de pronto-socorro.

MÉTODOS: Foram analisados dados referentes a vítimas de causas externas atendidas em pronto-socorro municipal localizado na zona Sul da cidade de São Paulo (SP) no período de 1/1/2002 a 11/1/2003. As informações foram obtidas a partir dos registros hospitalares. As 3.540 ocorrências foram localizadas geograficamente e os casos com endereço incompleto foram alocados com base numa escolha aleatória uniforme. Processos pontuais e técnicas de ondaletas foram utilizados para estimar a intensidade espacial, definida como o número esperado de eventos por unidade de área.

RESULTADOS: Do total de ocorrências georreferenciadas, 59\% foram acidentes e $40 \%$ agressões. A intensidade estimada indica que a distribuição espacial dos eventos não é homogênea, concentrando-se em dois distritos e três grandes avenidas localizados na zona Sul da cidade de São Paulo.

CONCLUSÕES: A utilização de ondaletas permite obter o número esperado de eventos e respectiva banda de confiança para quaisquer sub-regiões e, conseqüentemente, calcular estimativas dos riscos de ocorrência dos eventos de interesse, fornecendo subsídios para a definição de políticas para o enfrentamento da violência urbana. Dados hospitalares combinados com a metodologia para estimação da intensidade de ocorrência provaram-se úteis para estudar a violência urbana.

DESCRITORES: Violência. Zonas Urbanas. Registros Médicos. Sistemas de Informação Geográfica. Métodos e Procedimentos Estatísticos. Intensidade de processos pontuais.

\section{INTRODUCTION}

Urban violence is a public health problem associated to factors such as sex, age, socioeconomic conditions and cultural characteristics. ${ }^{4}$ Identifying and quantifying seasonal and spatial patterns of violence events is essential for better understanding its causes, and could provide input for the development of interventions and prevention policies to reduce health costs.

Most studies of external causes ${ }^{\mathrm{a}}$ that consider spatial analysis use lattice data, i.e., summary statistics aggregated by geographical areas. This data can be obtained from the Instituto Brasileiro de Geografia e Estatística (Brazilian Institute of Geography and Statistics, IBGE); Secretaria de Segurança Pública do Estado de São Paulo (Public Safety Department of the state of São Paulo) in the state of São Paulo; and Programa de Aprimoramento das Informações de Mortalidade no Município de São Paulo (Mortality Information
Enhancement Program of the city of São Paulo, PROAIM) in the city of São Paulo. They all provide data of external causes mortality based on police reports. Hospital records also constitute an excellent source of information on urban violence and provide details to allow an evaluation of spatial and temporal distributions of such events, but their potential is still not fully explored. Moreover, emergency room data provide case event data for which location information is known for each individual..${ }^{1,5}$ Case event data include detailed information and, in contrast with lattice data, are not subjected to the ecological fallacy. ${ }^{1,3}$

The objective of the present study was to estimate the spatial intensity function of urban violence events using hospital records and a methodology based on point processes and wavelet analysis. ${ }^{7, b, c}$ This approach constitutes a useful tool to analyze multidimensional

\footnotetext{
according to the International Classification of Diseases, Tenth Revision, external causes comprise deaths or injuries resulting from intentional injuries and poisoning (homicides and suicides) and unintentional (transport, occupational accidents and others) causes.

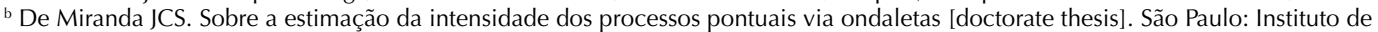
Matemática e Estatística da Universidade de São Paulo; 2003.

${ }^{c}$ De Miranda JCS, Morettin PA. Estimation of the density of point processes on R $^{m}$ via wavelets. São Paulo: IME-USP; 2005. (RT-MAT-NS; 2005-09).
} 
data, especially with respect to spatial or time-spatial distribution, for research and practical applications. It is also presented an allocation method for data georeferencing with incomplete address information.

\section{METHODS}

The data set comprised information on victims attended in the emergency room of a public hospital of the city of São Paulo, Southeastern Brazil, from January 1, 2002 to January 11, 2003. Data was provided by the Núcleo de Atenção à Vítima de Violência (Violence Victim Care Center, NAVV), a research group created in 2001 with the purpose of identifying potential violence causes and proposing actions for violence prevention. The hospital's front desk staff was trained to identify injured victims (by traffic accidents, falls, suicides, drowning, injuries caused by firearm, sharp or blunt objects, poisonings, burns and others) and to register the events in an appropriate file. This file includes personal information about the victim, home conditions, place and time where the event occurred, description of the event, how the victim arrived at the hospital (alone, brought by policemen, relatives, and others), psychological evaluation as well as signs of battered child syndrome, violence against women and violence against the elderly. The file also includes information about hospital discharge conditions and referral provided by NAVV. In the study period, 7,073 events were registered, of which 5,053 occurred within the boundaries of the city of São Paulo.

Each event was classified according to its description and reason for emergency room visit. This procedure was manually conducted due to lack of standardization of reference variables. First, each event was independently classified by two or three observers and then results were compared and inconsistent cases were discussed and classified in a consensual way. The following categories were considered:

- accidents: occupational accident; run-over accident; motorcycle rider accident; other transport accidents; accidental poisoning; animal bite; fall; other accidents;

- assaults: self-harm assault; sexual assault; assault by firearm, sharp or blunt objects; other assaults;

- legal interventions: events where the victim was brought to the hospital by policemen and that could not be classified into any of the previous sub-items;

- events of undetermined intent: events that could not be classified due to incomplete or incorrect information.
A fundamental step of spatial analysis is data georeferencing, i.e., to associate events to points on the Earth's surface by means of the latitude and longitude of the sites where they occurred.

The location of events was georeferenced using the Mapinfo Professional software, version 7.0, based on a map where streets are subdivided into segments. Each segment corresponds to locations situated between two successive corners. The program's automatic allocation procedure associates each event with the geographic coordinate of the centroid of the segment related to the address where the event occurred. This allocation procedure cannot be properly carried out when there is missing address information. An event is considered to have a complete address if it has both the street name and number of the location where it occurred. All events with street information but no numbers are assigned to the first segment of the street (or, alternatively, the last one) or disregarded. This allocation mechanism for incomplete addresses may introduce information bias, which could be reduced by using an alternative random uniform choice procedure. This procedure is based on the following steps: i) the events are coded 0-3 according to the type of information available about location; ii) a georeferencing criterion for each code is defined.

Codes and the criterion are described in Table 1 which also includes the number of events by allocation criterion. Only $2.3 \%$ of all 5,053 events studied had complete location information. Two main reasons might justify this small percentage: the data was not recorded with the purpose of being treated using spatial analysis tools and detailed information is usually inaccurately recalled in the case of sudden and traumatic events. There was no address information in $23.5 \%$ of the events and they could not be georeferenced. The remaining data $(74 \%)$ were georeferenced using the random uniform choice procedure. If the usual procedure were used, the events classified as code $2(70 \%)$ would be all assigned to the first street segment and those classified as code $3(4.7 \%)$ would be all assigned to the district centroid.

Count data occurring over time or at different points in space are usually modeled by point processes. ${ }^{2}$ This type of statistical technique is designed to estimate the intensity at which the events occur in fixed periods of time and areas. The intensity is defined as the expected number of events by unit area or over time. The methodology proposed by de Miranda and de Miranda \& Morettin $^{\mathrm{b}}$ based on wavelet series expansion method was used to obtain unbiased estimators of the intensity

\footnotetext{
a De Miranda JCS. Sobre a estimação da intensidade dos processos pontuais via ondaletas [doctorate thesis]. São Paulo: Instituto de Matemática e Estatística da Universidade de São Paulo; 2003.

${ }^{\mathrm{b}}$ De Miranda JCS, Morettin PA. Estimation of the density of point processes on $\mathrm{R}^{\mathrm{m}}$ via wavelets. São Paulo: IME-USP; 2005. (RT-MAT-NS; 2005-09).
} 
as well as of its variance. This is an alternative to loess, kernel and spline smoothers, commonly used to obtain an approximation of the intensity. ${ }^{5}$ A simulation study was conducted to show that the proposed method can generate more accurate results than other related approaches. An additional advantage of this method is the choice of a smoothing parameter; in the kernel and loess methods, this choice is based on a trial and error strategy. The proposed methodology includes a threshold procedure for correcting potential overfitting (in case of very large $\mathrm{J}_{1}$ or $\mathrm{J}_{2}$, as described in the "Estimation of the intensity" subsection).

The proposed methodology can be applied to a vast class of point processes since the required assumptions are extremely mild. More specifically, it is only required that the density exists and is a locally square integrable function. It can also be applied to estimate confidence bands for the desired intensities and to compare intensities associated to different sub-regions (or time periods). A non-internally correlated (NIC) process, where the covariance among the number of events occurring in any two disjoint regions is null is also required to estimate confidence bands for the intensity. Point processes as such seem appropriate to model the study data since it is reasonable to consider that events occurring in one region are not related to the occurrence of events in a disjoint region. The existence of neighboring regions with many (or few) occurrences does not imply that the occurrences in these regions are correlated, but rather that these regions have certain characteristics that make them more (or less) prone to event occurrence. The methods are detailed in the Appendix.

\section{RESULTS}

Victims' age ranged between 0 to 89 years (mean $=29.4$ years, standard deviation $=14.4$ years). There was a higher proportion of male victims $(68 \%)$ but age distributions were similar for both men and women. Of all events, 59\% were accidents and 39\% were assaults. Traffic accidents (run-over accident, motorcycle rider accidents and other transport accidents) were the most frequent, accounting for $86 \%$ of all accidents. The majority of assault cases $(67 \%)$ were classified as "other assaults". The mean number of events was greater during weekends and lesser on Tuesdays, suggesting a possible seasonality. In general, this same pattern is also seen when assault and accident data are analyzed separately. Table 2 shows the number of observed events by type and day of the week. These data suggests varied occurrence of violence events throughout the week. For example, occupational accidents occurred more frequently on Fridays while other accidents and assaults are mainly seen during the weekend.

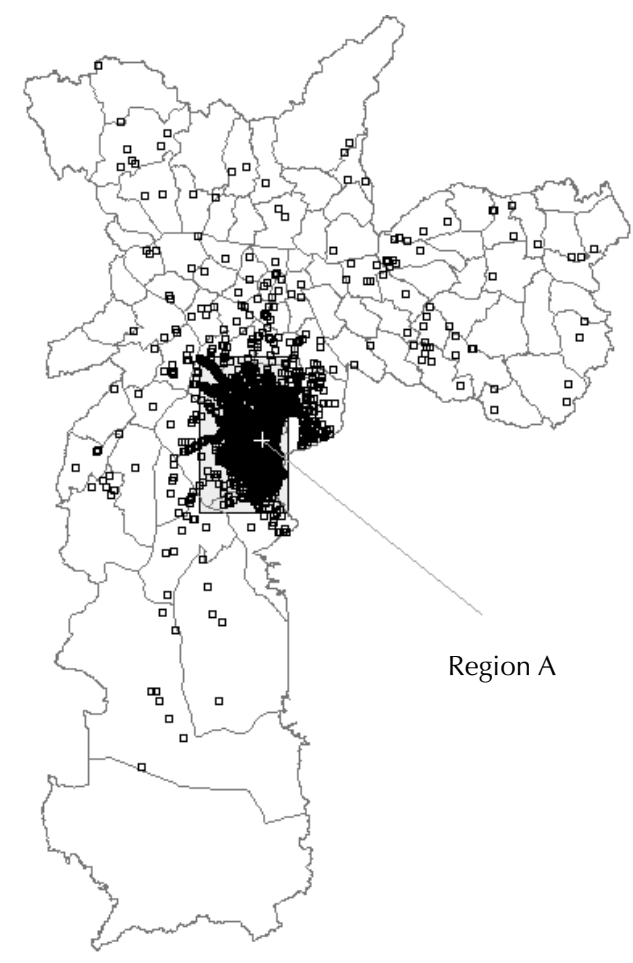

Figure 1. Distribution of events in the city of São Paulo, Southeastern Brazil, 2002-2003. ( $n=3,865)$.

Figure 1 shows the spatial distribution of the 3,865 events georeferenced according to the criterion described in Table 1. Events were distributed throughout the city and showed higher concentration in the hospital vicinity. This is an expected finding since rescue services usually move the victims to the closer public hospital where there are vacancies and a medical team available prepared to assist the specific type of injury. Also bearing in mind that the hospital studied is a reference trauma center, the pattern depicted in Figure 1 is expected.

Intensity was estimated in a limited region, designated as A, close to the hospital (Figure 1). This region has $83.4 \mathrm{~km}^{2}(6.86 \mathrm{~km}$ in the East-West direction by 12.15 $\mathrm{km}$ in the North-South direction) and includes 3,430 georeferenced points, of which $59 \%$ are accidents and $40 \%$ assaults. Figure 2 shows the enlarged A region with events superimposed on a street map. It shows a concentration of events around the hospital area and also some clusters of events near main roads, such as Bandeirantes, Jabaquara and Cupecê avenues, in the southern area of the city.

For wavelet analysis, the rectangular region A was subdivided into elementary (rectangular) regions (ER) with their size given by $\mathrm{T}_{1} \mathrm{~T}_{2} / 2^{\mathrm{J}_{1} \mathrm{~J}_{2}+2}$, where $\mathrm{T}_{1}$ and $\mathrm{T}_{2}$ are of the width and length measures of region $A$ and $J_{1}$ and $J_{2}$ are parameters controlling for estimation precision. The 
Table 1. Georeferencing codes and criterion for event allocation. City of São Paulo, Southeastern Brazil, 2002-2003.

\begin{tabular}{|c|c|c|c|c|}
\hline \multirow[b]{2}{*}{ Code } & \multicolumn{2}{|c|}{ Random uniform choice procedure } & \multicolumn{2}{|c|}{ Case } \\
\hline & Available information & Allocation criterion & $\mathrm{n}$ & $\%$ \\
\hline 0 & $\begin{array}{l}\text { No information about event address (missing } \\
\text { street or district) }\end{array}$ & Georeferencing is not feasible & 1,188 & 23.5 \\
\hline 1 & Complete address (street name and number) & Georeferencing using the usual procedure & 117 & 2.3 \\
\hline 2 & Incomplete address (missing number) & $\begin{array}{l}\text { Georeferencing by street segment selected ran- } \\
\text { domly among all possible street segments into } \\
\text { which the street of occurrence was subdivided. }\end{array}$ & 3,514 & 69.5 \\
\hline \multirow[t]{2}{*}{3} & Only information about district of occurrence & $\begin{array}{l}\text { Georeferencing by street segment selected } \\
\text { uniformly among all possible street segments } \\
\text { within the district of occurrence. }\end{array}$ & 234 & 4.7 \\
\hline & & Total & 5,053 & $100 \%$ \\
\hline
\end{tabular}

greater $\mathrm{J}_{1}$ and $\mathrm{J}_{2}$, the smaller ER size and, consequently, the greater the estimation precision. It was assumed that $\mathrm{J}_{1}=3$ and $\mathrm{J}_{2}=4$ resulting in $\mathrm{ER}$ size $=6.86 \mathrm{~km} \times 12.15$ $\mathrm{km} / 2^{3+4+2}=0.163 \mathrm{~km}^{2}$. The choice of elementary regions measuring $0.163 \mathrm{~km}^{2}$ each $(379.7 \mathrm{~m}$ in the East-West direction by $428.9 \mathrm{~m}$ in the North-South direction) seems suitable since, in most cases, it is not expected that locations can be identified at a precision greater than $380 \mathrm{~m}$ along street segments.

The minimum and maximum estimated intensities were zero and 376.8 events by $\mathrm{km}^{2}$, respectively (mean $=41.8$ events by $\mathrm{km}^{2}$ ). Estimated confidence bands with at least $75 \%$ confidence coefficients (not shown) were applied to identify regions with a significantly different number of events. To facilitate visualization, the estimated intensities were grouped into 10 categories as shown in Figure 3. It shows a non-homogeneous spatial distribution of events. Regions with more than 128 expected events by $\mathrm{km}^{2}$ are mostly in the vicinity of the hospital. Two sequences of elementary regions with more than 32 expected events by $\mathrm{km}^{2}$, located at Bandeirantes and Jabaquara Avenues were also observed.

Table 2. Number of events by type and day of the week. City of São Paulo, Southeastern Brazil, 2002-2003.

\begin{tabular}{|c|c|c|c|c|c|c|c|c|}
\hline \multirow{2}{*}{ Event } & \multicolumn{7}{|c|}{ Day of the week } & \multirow[b]{2}{*}{ Total } \\
\hline & Sun & Mon & Tue & Wed & Thu & Fri & Sat & \\
\hline \multicolumn{9}{|l|}{ Accident } \\
\hline Occupational accident & 12 & 34 & 35 & 44 & 46 & 54 & 23 & 248 \\
\hline Run-over accident & 142 & 125 & 132 & 137 & 160 & 162 & 179 & 1037 \\
\hline Motorcycle rider accident & 124 & 95 & 102 & 120 & 108 & 138 & 122 & 809 \\
\hline Other transport accidents & 146 & 94 & 73 & 83 & 82 & 83 & 167 & 728 \\
\hline Fall & 4 & 16 & 7 & 9 & 14 & 9 & 6 & 65 \\
\hline Accidental poisoning & 0 & 0 & 0 & 0 & 4 & 1 & 1 & 6 \\
\hline Animal bite & 5 & 1 & 0 & & 0 & 0 & 3 & 9 \\
\hline Other accidents & 4 & 14 & 9 & 20 & 17 & 8 & 11 & 83 \\
\hline Total & 437 & 379 & 358 & 413 & 431 & 455 & 512 & 2985 \\
\hline \multicolumn{9}{|l|}{ Assault } \\
\hline Self-harm assault & 12 & 13 & 16 & 20 & 14 & 10 & 15 & 100 \\
\hline Sexual assault & 1 & 4 & 5 & 6 & 8 & 4 & 2 & 30 \\
\hline By firearm & 49 & 47 & 54 & 37 & 38 & 50 & 89 & 364 \\
\hline By sharp or blunt objects & 30 & 28 & 19 & 20 & 20 & 19 & 27 & 163 \\
\hline Other assaults & 261 & 198 & 141 & 160 & 161 & 162 & 241 & 1324 \\
\hline Total & 353 & 290 & 235 & 243 & 241 & 245 & 374 & 1981 \\
\hline Legal intervention & 0 & 0 & 0 & 0 & 0 & 0 & 1 & 1 \\
\hline Events of undetermined intent & 11 & 10 & 5 & 10 & 21 & 11 & 18 & 86 \\
\hline Total & 801 & 679 & 598 & 666 & 693 & 711 & 905 & 5,053 \\
\hline
\end{tabular}




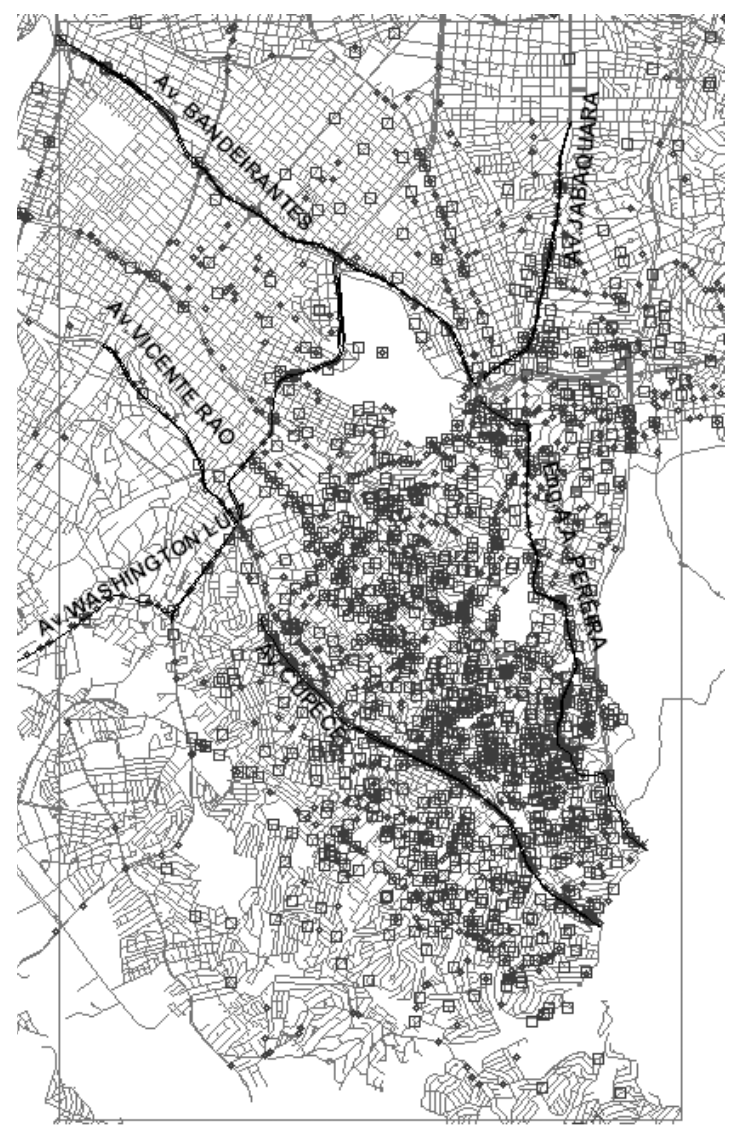

Accident (O) Assault ( $\square$ )

Figure 2. Distribution of events in region A. City of São Paulo, Southeastern Brazil, 2002-2003.

\section{DISCUSSION}

Hospital records combined with methodological tools, e.g. wavelet series expansion method, to estimate the intensity are a valuable source of information on urban violence. However, the present study showed that more attention should be given to the quality of hospital records and database with special concern to information about location and time of event occurrence.

The estimated intensity function provides the expected number of events for any subregion and may be used to calculate spatial relative risk estimates that could contribute to decision-making processes for public policies. These risk estimates could be calculated considering many possibilities. For example, Lima ${ }^{a}$ presents spatial relative risks between assault against males versus assault against females and also between transport accident events occurring along different days of the week.

Data from a single hospital is not representative of the spatial distribution of events occurring in other nonneighboring regions. In the present study, intensity was estimated only in a selected area close to the hospital under investigation (region A). The reasons for the possible underestimation of the intensity are the unknown number of violent events referred to other hospitals and the lack of georeferencing for some events. Yet the purpose of the present study was to illustrate how well wavelet method can be applied in hospital record analysis. Other larger and more carefully designed studies can further the knowledge on urban violence in the city of São Paulo.

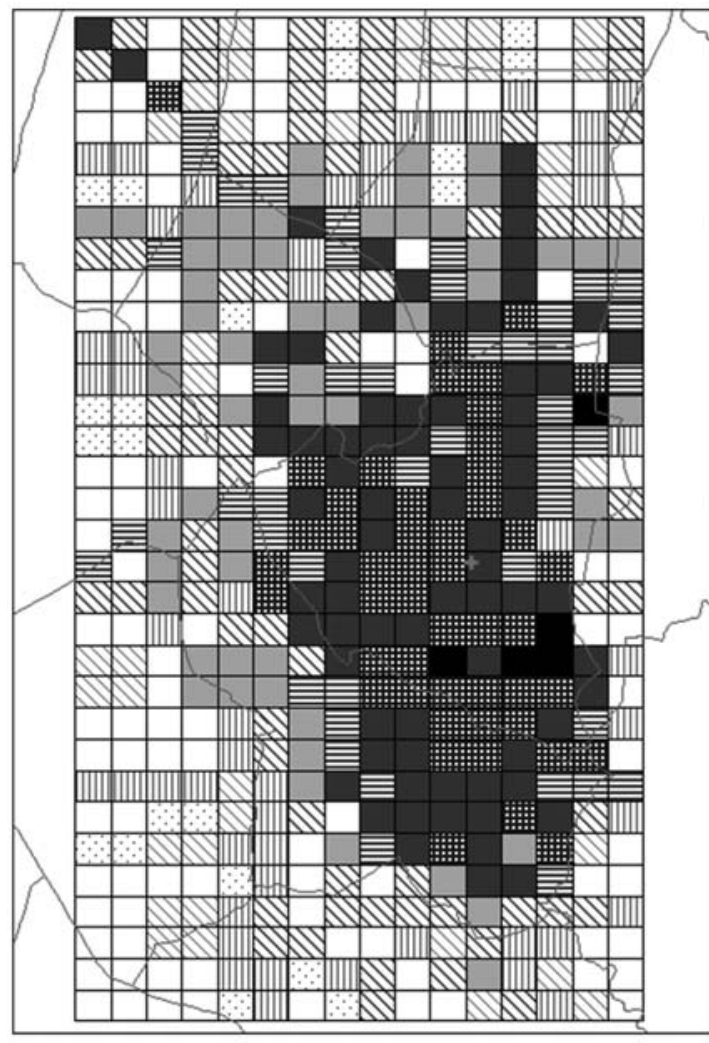

\begin{tabular}{|c|c|c|c|}
\hline Legend & Category & $\begin{array}{c}\text { Number of } \\
\text { elementary regions }\end{array}$ & $\%$ \\
\hline & 0 to 1 & 103 & 20.1 \\
\hline & 1 to 2 & 21 & 4.1 \\
\hline & 2 to 4 & 36 & 7.0 \\
\hline & 4 to 8 & 53 & 10.4 \\
\hline & 8 to 16 & 68 & 13.3 \\
\hline & 16 to 32 & 58 & 11.3 \\
\hline & 32 to 64 & 45 & 8.8 \\
\hline & 64 to 128 & 75 & 14.6 \\
\hline & 128 to 256 & 48 & 9.4 \\
\hline & 256 or more & 5 & 1.0 \\
\hline & Total & 512 & 100 \\
\hline
\end{tabular}

Figure 3. Categories of the estimated intensity (number of events by $\mathrm{km}^{2}$ ). City of São Paulo, Southeastern Brazil, 2002-2003. 


\section{APPENDIX}

Wavelets are simple functions, of which linear combinations are used to approximate other more complicated functions. The approximation involves linear combinations of functions (wavelets). The most suitable set of functions for this purpose is the $\mathrm{L}^{2}(\mathbb{R})$ space, that is, the space of all measurable square integrable function on the real line $\mathbb{R}$. The basic idea is to consider dilations and translations of one function $\psi$, called the mother wavelet, and form a set of functions $\left\{\psi_{i, j} \mid i, j \in \mathbb{Z}\right\}$ obtained from dilations and translations of $\psi$ as:

(A.1) $\quad \psi_{i, j}(t)=2^{j / 2} \psi\left(2^{j} t-i T\right), t \in \mathbb{R}, T$ is a known constant.

The function $\psi_{0,0}$ is obtained from another function, $\psi_{0}(t)$, known as the father wavelet. In this study, functions of the Haar family were considered for such purposes. They are defined by (A.1) with $\psi_{0,0}$ given by

$\Psi_{0,0}(x)=\left\{\begin{array}{l}1 / \sqrt{T}, 0 \leq x<T / 2 \\ -1 / \sqrt{T}, T / 2 \leq x<T \\ 0, \text { otherwise }\end{array}\right.$

and with the associated father wavelet given by

$\psi_{0}(x)=\left\{\begin{array}{l}1 / \sqrt{T}, 0 \leq x<T \\ 0, \text { otherwise }\end{array}\right.$

For practical purposes it is sufficient to work with wavelets defined on $[0, T] \subset \mathbb{R}$. In this case, it is convenient to use an orthonormal wavelet base formed by

$\mathrm{B}=\left\{\psi_{0}, \psi_{i, j} \mid i, j \in \mathbb{Z}, j \geq 0,0 \leq i \leq\left(2^{j}-1\right)\right\}$, where the integer $i$ is associated with location and the integer $j$ with scale. The indices $i$ and $j$ are related to the translation and dilation levels of the mother wavelet, respectively.

Considering a function $f$ that belongs to the $\mathrm{L}^{2}(\mathbb{R})$ space with support on $[0, T]$, the wavelet series expansion is given by

$$
\begin{aligned}
& f(x)=\alpha_{0} \psi_{0}(x)+\alpha_{(0,0)} \Psi_{(0,0)}(x)+ \\
& \alpha_{(0,1)} \psi_{(0,1)}(x)+\alpha_{(0,2)} \Psi_{(0,2)}(x)+\ldots=\sum_{\eta \in Z} \alpha_{\eta} \psi_{\eta}(x)
\end{aligned}
$$

where $\alpha_{\eta} \in \mathbb{R}$ and $Z$ represents the set of all indices

$$
\begin{aligned}
& \{0,(0,0),(0,1),(0,2), \ldots\}= \\
& \left\{0,(i, j) \mid i, j \in \mathbb{Z}, j \geq 0,0 \leq i \leq\left(2^{j}-1\right)\right\}
\end{aligned}
$$

in the base $B$; under this notation, the base can be represented by $B=\left\{\psi_{\eta} \mid \eta \in Z\right\}$.

Assuming that $N$ is a point process with unknown density function $v$ and $\mathbf{A}$ is either the geographical region or the time period under study, the expected number of events that occur in $\mathbf{A}$ is defined as $\mathrm{E} N(A)=\int_{\mathrm{A}} \mathrm{U}(x) d x$.

The one-dimensional case (temporal). Taking $0 \leq j \leq J$ and $0 \leq i \leq\left(2^{j}-1\right)$ the set of wavelets considered in the expansion (A.2) is limited so that an approximation of $v$ via wavelets up to $J$-th scale is given by

$$
v_{J}(x)=\sum_{\eta \in Z_{J}} \beta_{\eta} \psi_{\eta}(x) .
$$

For example, if $J=2$ then $Z_{J}=\{0,(0,0),(0,1),(1,1)$, $(0,2),(1,2),(2,2),(3,2)\}$ where the first element refers to the father wavelet, $\psi_{0}$, and the other ones refer to the $\psi_{(i, j)}=\psi_{i, j}$ wavelets.

An unbiased estimator of (A.3) is given by

$$
\hat{v}_{J}(x)=\sum_{\eta \in Z_{J}} \hat{\beta}_{\eta} \psi_{\eta}(x)
$$

with $\hat{\beta}_{\eta}=\sum_{i \in I}\left[\psi_{\eta}\left(t_{i}\right) N\left(\mathrm{~d} t_{i}\right)\right]$ denoting an unbiased estimator of $\beta_{\eta}$, where $t_{i}$ is the instant of occurrence of the $i$-th event and $\mathrm{N}\left(\mathrm{d} t_{i}\right)$ represents the number of events occurred in an infinitesimal region which contains the point $\mathrm{t}_{i} \in[0, T]$.

An unbiased estimator of the variance of $\hat{\beta}_{\eta}$ is

$$
\widehat{\operatorname{Var}}\left(\hat{\beta}_{\eta}\right)=\sum_{i \in I}\left[\psi_{\eta}^{2}\left(t_{i}\right) N^{2}\left(\mathrm{~d} t_{i}\right)\right],
$$

and an unbiased estimator of the variance of $\hat{v}_{J}(x)$ is

$$
\begin{aligned}
& \widehat{\operatorname{Var}}\left(\hat{\mathrm{v}}_{J}(x)\right)= \\
& \sum_{\eta} \sum_{\xi}\left[\sum_{i \in I}\left[\psi_{\eta}\left(t_{i}\right) \psi_{\xi}\left(t_{i}\right) N^{2}\left(\mathrm{~d} t_{i}\right)\right] \psi_{\eta}(x) \psi_{\xi}(x)\right]
\end{aligned}
$$

with $\eta, \xi \in Z_{J}$.

Note that (A.4) and (A.6) are also asymptotically, in relation to $J$, unbiased for $v$ and $\operatorname{Var}(\hat{v})$, respectively. The magnitude of the bias measured in the $\mathrm{L}^{2}$ norm for $\hat{\mathrm{v}}_{J}$ exponentially decreases with $J$. A detailed study of the convergence rate and bounds for the bias of these estimators is presented in de Miranda. ${ }^{a}$

The two-dimensional case (spatial). For spatial densities, two coordinates must be considered. The estimators for $v_{J}(x)$ and $\beta_{\eta}$ assume similar forms to those presented in the one-dimensional case. Now, $\eta$ belongs to the set $Z_{J}=Z_{J_{1}} \times Z_{J_{2}}$, where $J_{i}$ corresponds to the maximum scale for the $i$-th coordinate. Since $\psi_{\eta}(x, y)=\psi_{\left(\eta_{1}, \eta_{2}\right)}(x, y)=\psi_{\left(\eta_{1}\right)}(x) \psi_{\left(\eta_{2}\right)}(y)$ is also an orthonormal base ${ }^{6}$ it can be written as $\hat{\mathrm{v}}_{J=\left(J_{1}, J_{2}\right)}(x)=\sum_{\eta=\left(\eta_{1}, \eta_{2}\right)} \hat{\beta}_{\left(\eta_{1}, \eta_{2}\right)} \Psi_{\left(\eta_{1}, \eta_{2}\right)}(x) \quad$ and $\hat{\beta}_{\left(\eta_{1}, \eta_{2}\right)}=\sum_{i \in I}\left[\Psi_{\left(\eta_{1}, \eta_{2}\right)}\left(\mathbf{t}_{i}\right) N\left(\mathbf{d t}_{i}\right)\right]$ where $\eta_{1} \in Z_{1}, \eta_{2} \in Z_{2}$ and $\eta=\left(\eta_{1}, \eta_{2}\right) \in\left(Z_{1} \times Z_{2}\right)$. Note that now $\mathbf{t}_{i}=\left(x_{i}, y_{i}\right)$ represents a point in $\mathbf{A}$. 
Estimators of the variance of $\hat{\beta}_{\left(\eta_{1}, \eta_{2}\right)}$ and $\hat{v}_{\left(J_{1}, J_{2}\right)}(x)$ are obtained as presented in (A.5) and (A.6).

Threshold procedure. A threshold procedure can be used to evaluate the significance of the wavelet coefficients based on Chebyshev's inequality. The procedure is equivalent to rejecting $\mathrm{H} 0: \beta_{\eta}=0$ versus $\mathrm{H} 1: \beta_{\eta} \neq 0$ for all $\eta \in Z_{J}$ when $\left|\hat{\beta}_{\eta}\right| \geq \lambda \sqrt{\widehat{\operatorname{Var}}\left(\hat{\beta}_{\eta}\right)}$. Taking $\lambda=2$ the confidence level is $75 \%$.

This procedure provides a threshold estimated intensity which is computed using only those wavelet coefficients that significantly differ from zero. It corrects potential overfitting due to large $J_{i}$ values.

\section{ACKNOWLEDGMENTS}

To Dr. José Carlos Simon de Miranda of Instituto de Matemática e Estatística at USP for his comments on the statistical methodology, Dr. Alfésio Luis F. Braga of Universidade de Santo Amaro and Dr. Luiz Alberto A. Pereira of Faculdade de Medicina at USP for their help with classification of the events.

\section{REFERENCES}

1. Bailey TC. Spatial statistical methods in health. Cad Saude Publica. 2001;17(5):1083-98. doi:10.1590/ S0102-311X2001000500011

2. Diggle PJ. Statistical analysis of spatial point patterns. New York: Academic Press; 1983.

3. Elliott $\mathrm{P}$, Wakefield J. Bias and confounding in spatial epidemiology. In: Elliott P, Wakefield J, Best N, Briggs D, editors. Spatial epidemiology. New York: Oxford University Press; 2000. p.68-84.

4. Jorge MHPM, Yunes J. Violência e saúde no Brasil. Rev USP. 2001;51:114-27.

5. Kaluzny SP, Vega SC, Cardoso TP, Shelly AA. S+ spatial stats. User's manual for Windows and UNIX. New York: Springer; 1998.

6. Meyer Y. Ondelettes et algorithmes concurrents. Paris: Hermann; 1992.

7. Morettin PA. Ondas e ondaletas: da análise de Fourier à análise de ondaletas. São Paulo: Edusp; 1999.

Article based on the doctorate thesis by LP Lima presented to Faculdade de Medicina of Universidade de São Paulo in 2005. LP Lima was partially supported by Conselho de Desenvolvimento Científico e Tecnológico (CNPq - doctorate scholarship). Research partially funded by Fapesp (n.01/12913-3; n.04/15304-6) and CNPq (n.306180/88-0 RN). 